\title{
Tamización de malaria en donantes de sangre de Cali, Colombia
}

\author{
Carmen M. Castillo, Carolina Ramírez \\ Centro Internacional de Entrenamiento e Investigaciones Médicas (CIDEIM), Cali, Colombia.
}

Introducción. En Colombia existe déficit de unidades de sangre. En ciudades como Cali este déficit se agrava por el rechazo de donantes debido al riesgo de transmitir malaria; aunque en la ciudad no hay transmisión de malaria, está próxima a la Costa Pacífica, zona de alta transmisión de malaria en el país. En los bancos de sangre, la tamización de malaria está basada solamente en una entrevista. Una prueba de laboratorio para malaria podría mejorar la selección de los donantes y, así, incrementar el número de unidades de sangre disponibles. Objetivo. Evaluar las pruebas de gota gruesa, ELISA-IgG y ELISA-HRPII usando la PCR semianidada como prueba de referencia en la tamización de donantes de sangre en Cali.

Materiales y métodos. El estudio se llevó a cabo en un banco de sangre de Cali entre febrero y mayo de 2002. Se practicaron gota gruesa, ELISA-IgG y ELISA-HRPII (Pan Malaria Antibody ELISA y Malaria Ag CELISA, Cellabs, Australia) y sus resultados se compararon con la PCR semianidada. Se evaluaron 286 muestras, 115 eran donantes rechazados únicamente por tener antecedentes de haber vivido o viajado a zonas endémicas en el último año y 171 eran donantes aceptados.

Resultados. Ninguna muestra tuvo resultado positivo con las pruebas realizadas.

Conclusión. Los donantes rechazados basados en la entrevista podrían haber sido aceptados según las pruebas de laboratorio. Con el propósito de mejorar el proceso de tamización, sugerimos realizar una prueba de laboratorio a los donantes que son rechazados por el riesgo potencial de transmitir malaria. Se requieren estudios adicionales que permitan seleccionar la prueba más adecuada.

Palabras clave: malaria, donadores de sangre, bancos de sangre, tamizaje.

\section{Malaria screening in blood donors in Cali, Colombia}

Introduction. In Colombia, blood units for transfusions are in short supply. In Cali, a city in central western Colombia, the situation is exacerbated by a policy of scrupulous rejection of blood donors who may have been exposed to malaria infection. Cali is free of malaria transmission, but it lies close to the Pacific Coast, a highly endemic region. Currently, malaria screening in potential blood donors is based only on an interview. A more sensitive and objective malaria test will increase the number of acceptable donors and, hence, increase the available blood supply.

Objective. Three malaria tests were evaluated, thick smear, ELISA-IgG and ELISA-HRPII, using a semi-nested PCR as gold standard.

Material and methods. The study was undertaken in a blood bank of Cali, from February to May 2002, where 286 individuals were examined. Blood thick smear, ELISA-IgG and ELISA-HRPII (Pan Malaria Antibody ELISA and Malaria Ag CELISA) results were compared to semi-nested PCR data.

Results. Of the 286 donors tested, 115 were rejected because of a history of traveling or living in a malaria endemic area within the last year. However, none of these applicants were malariapositive using the three testing methods.

Conclusion. To improve the screening process, laboratory tests for malaria are recommended for donors who are exposed to a risk of malaria infection. Additional studies are necessary for selection of most sensitive test, however.

Key words: malaria, blood donors, blood banks, screening. 
Si se compara con las recomendaciones de la Organización Mundial de la Salud (5 por 100 habitantes por año), las 1,1 unidades de sangre por 100 habitantes por año disponibles en Colombia representan un considerable déficit (1). Esta situación empeora con el actual conflicto interno, ya que la demanda de unidades de sangre es alta. Además de la escasez de donantes, una de las principales causas del déficit de unidades de sangre es el alto índice de serorreactividad en el país $(9,8 \%)$ debido a que los donantes son, en su mayoría, familiares o por reposición y, a veces, obligados a donar (1-3).

Esto facilita que algunos donantes, por interés o presión, nieguen información relevante que los excluiría como donantes (4). Además, en ciudades cercanas a las zonas endémicas de malaria, un alto número de donantes son rechazados o diferidos por sospecha de infección con Plasmodium sp. Un estudio realizado por Cortés et al. en 1999 mostró que el $23,6 \%$ de los donantes rechazados en el Valle del Cauca son debido al riesgo de infección por malaria (5), y era la causa principal de rechazo.

De acuerdo con el Ministerio de Protección Social de Colombia, la tamización de malaria en donantes de sangre no es obligatoria en las regiones en donde no hay transmisión de la infección. Por el contrario, en las regiones endémicas es obligatorio realizar la gota gruesa, como prueba de tamización a todos los donantes de sangre (6).

Por esta razón, en ciudades como Cali, donde no hay transmisión de malaria, pero sí un flujo constante de personas desde y hacia las zonas endémicas cercanas, no se aplica una prueba de laboratorio para la detección de malaria y, en su lugar, la selección de los donantes sin riesgo de transmitir malaria se hace a través de la entrevista del banco de sangre.

Correspondencia:

Carmen M. Castillo, Centro Internacional de Entrenamiento e Investigaciones Médicas (CIDEIM), Avenida 1N \#3-03. Cali, Colombia.

Teléfono: (2) 668 2164: fax: (2) 6672989.

carmen_castillo@cideim.org.co

Recibido: 17/09/04; aceptado: 18/03/05
De acuerdo con el manual de normas técnicas y procedimientos para bancos de sangre del Ministerio de Protección Social, los donantes que han visitado una zona endémica de malaria en los últimos 12 meses deben ser diferidos durante un año y quienes han vivido en estas zonas diferidos por tres años (6).

Actualmente, la tamización de malaria en bancos de sangre en Cali y en las ciudades de Colombia sin transmisión autóctona de malaria está basada en las preguntas incluidas en la encuesta sobre visitas o estadías en zonas endémicas, lo cual involucra, por ende, el conocimiento que los entrevistadores y los potenciales donantes tienen sobre las regiones endémicas de malaria en el país y sobre la conciencia y memoria de este último. De esta manera, al no usarse un método objetivo para medir el riesgo de transmisión de malaria se podría estar rechazando donantes en forma errada y aceptando posibles donantes infectados.

Cali es la principal ciudad del suroccidente del país, con una población de tres millones de habitantes, aproximadamente. En Cali, cada año se diagnostican entre 900 y 1.500 casos de malaria; es una enfermedad de notificación obligatoria ante la Secretaría de Salud Pública Municipal. Todos son casos importados, principalmente, de la Costa Pacífica, zona que aporta el $20 \%$ de la incidencia anual de malaria del país (7).

La implementación de una prueba de laboratorio para malaria en los bancos de sangre en ciudades como Cali podría ser útil para verificar objetivamente la seguridad de las unidades de sangre y, así mismo, recuperar donantes que actualmente no se aprovechan.

Varios estudios previos en Colombia han mostrado que el riesgo potencial de transmitir malaria por la vía de la transfusión de sangre es alto. En 1999, en un estudio realizado en el Hospital San Vicente de Paúl de Medellín, se determinó una prevalencia de seropositividad para malaria de 1,8\% entre 392 sueros de donantes evaluados (8) y, previamente, en 1982, un estudio realizado en el Hospital Militar de Bogotá mostró que el 8,6 por mil de las 3.114 muestras evaluadas eran positivas para anticuerpos 
antimaláricos; durante este estudio se detectaron tres casos de malaria transfusional (9). Aunque se sabe que la medición de anticuerpos no significa necesariamente infección activa, sí define la existencia del riesgo.

Existen diferentes pruebas de laboratorio que podrían ser utilizadas para la tamización de donantes, las cuales van desde las más sencillas y menos costosas como la gota gruesa hasta las más complejas y costosas como la reacción en cadena de la polimerasa, pruebas para determinar antígenos o para determinar anticuerpos contra Plasmodium sp., además, existen las pruebas rápidas que también podrían ser evaluadas para este fin.

Con el objetivo de determinar la utilidad de algunas pruebas de laboratorio en la tamización de malaria se evaluaron la gota gruesa, el ELISA para detección de IgG anti-Plasmodium y el ELISA para la detección de la proteína HRPII de $P$. falciparum (Cellabs, Australia) en muestras de sangre de donantes potenciales. Los resultados se compararon con la PCR semianidada.

\section{Materiales y métodos}

\section{Participantes y recolección de muestras}

Este estudio se realizó en uno de los principales bancos de sangre de Cali. La población estuvo constituida por los donantes potenciales que llegaron entre febrero y mayo de 2002, un período que coincide con la mayor transmisión de malaria en las regiones endémicas vecinas.

Los donantes se dividieron en dos grupos: el grupo de donantes "aceptados" y el grupo de donantes "rechazados". El grupo de "aceptados" comprendía las personas que según la entrevista del banco de sangre no tenían ningún riesgo de transmitir enfermedad, y el grupo de "rechazados", personas con historia de haber vivido o viajado a zonas endémicas de malaria en los últimos 12 meses. Las personas que fueron rechazadas por cualquier otra causa no fueron elegibles para el estudio. El estudio contó con una entrevista adicional a la entrevista que realizó el banco de sangre. Las entrevistas del banco de sangre fueron realizadas por profesionales de medicina encargados de esta función.
El tamaño de muestra del grupo de "rechazados" se calculó considerando que $20 \%$ de estos donantes eran realmente positivos para malaria; para el grupo de "aceptados" se usó el método de "control de calidad doble de lotes" de Lemeshow y Taber (10), considerando una proporción mínima de casos positivos de $0,08 \%$ y una proporción máxima de $4 \%$.

Todas las muestras se obtuvieron a través de la participación voluntaria de los donantes quienes firmaron un consentimiento informado. Este estudio fue aprobado por el comité de ética del CIDEIM.

Se obtuvieron $10 \mathrm{ml}$ de sangre total por punción venosa de cada participante. La gota gruesa fue realizada inmediatamente y el resto de la muestra fue congelada en viales a $-20^{\circ} \mathrm{C}$. Estas muestras se guardaron y las pruebas de ELISA IgG, ELISA para la detección de HRPII y PCR se realizaron ocho meses después.

\section{Pruebas de laboratorio}

Para la gota gruesa se prepararon dos láminas, una para diagnóstico y otra para control de calidad. En cada lámina se realizaron dos gotas gruesas. Inicialmente cada lámina fue tratada con azul de metileno para remover la hemoglobina y, luego, se coloreó con Giemsa $1 \%$ en solución tamponada $(\mathrm{pH} 7,2)$ durante 10 minutos. Se usó el microscopio de luz para la lectura de la lámina usando el objetivo de 100X. La gota gruesa se consideró negativa después de examinar 200 campos microscópicos sin evidencia de parásitos. Un bacteriólogo experimentado preparó y revisó las dos gotas gruesas de cada lámina. El control de calidad se hizo el $100 \%$ de las láminas y este fue realizado por un bacteriólogo de CIDEIM entrenado en el diagnóstico de malaria.

Para realizar el ELISA-IgG y ELISA HRPII se usaron estuches comerciales de los Laboratorios Cellabs de Australia. Se siguieron todas las indicaciones de manufactura para su realización. ELISA IgG es un ELISA sandwich o indirecto, la cantidad de color generada es proporcional a la cantidad de anticuerpos presentes en el suero evaluado. La ELISA-HRPII es una prueba cualitativa empleada para detectar la presencia de la proteína rica en histidina del $P$. falciparum. 
El color generado indica que el antígeno está presente en la muestra.

Además, para los controles positivos y negativos suministrados con los estuches se usaron 5 controles positivos de pacientes con diagnóstico de malaria confirmado por gota gruesa en el Laboratorio de Parasitología de la Universidad del Valle y 8 controles negativos de personas que nunca habían vivido o viajado a una zona endémica para malaria. Estos ELISA son pruebas sistematizadas y el tiempo que toma su realización es de tres horas, en promedio.

\section{Reacción en cadena de la polimerasa (PCR)}

Para la extracción del ADN se usó el estuche QIAamp ADN (Quiagen, USA) usando $200 \mu \mathrm{l}$ de sangre periférica. Para el diagnóstico de malaria se desarrolló una PCR múltiple semianidada basada en la amplificación del gen del rADN de la subunidad ribosómica 18S, empleando los 7 oligonucleótidos descritos por Rubio et al. (11).

En la primera reacción de PCR se utilizaron: el oligonucleótido reverso (R) UNR (UNiversal) que anilla con ADN de vertebrados y de todas las especies de Plasmodium, y los oligonucleótidos directos ( $F$, por su traducción del inglés forward) HUF (para amplificar ADN de origen $\underline{H U}$ mano) y PLF ( PLasmodium) que anillan con ADN de vertebrados (incluso humanos) y de todas las especies de Plasmodium, respectivamente. En esta primera reacción se amplificó una banda de
$231 \mathrm{pb}$, correspondiente al control interno de la reacción UNR-HUF, y una banda de 783-821 pb producto de la amplificación UNR-PLF para cualquier especie de Plasmodium (figura 1a).

La reacción de amplificación en la primera PCR se realizó en un volumen final de $50 \mu$ que contenía $0,5 \mathrm{pmol} / \mathrm{ml}$ de los cebadores UNR y PLF, 0,025 $\mathrm{pmol} / \mathrm{ml}$ de HUF, 0,05 U/ml Taq ADN polimerasa (Promega, USA), $200 \mathrm{mM}$ de dNTP, $2 \mathrm{mM}$ de $\mathrm{MgCl}_{2}$ y $1 \mathrm{X}$ de solución tampón.

La segunda PCR se llevó a cabo utilizando $1 \mathrm{ml}$ del producto de la primera reacción de amplificación. Se usó el oligonucleótido $P L F$ y los oligonucleótidos reversos (R) MAR, FAR, OVR y $V I R$ que anillan específicamente con ADN de las diferentes especies de Plasmodium: P. malariae (MA), P. falciparum (FA), P. ovale (OV) y P. vivax $(\mathrm{VI})$, respectivamente (figura $1 \mathrm{~b}$ ).

La segunda reacción se llevó a cabo en un volumen final de $25 \mathrm{ml}$ que contenía $0,15 \mathrm{pmol} / \mathrm{ml}$ de los cebadores PLF y FAR, 0,1 pmol/ml de MAR, OVR y $V I R, 0,1 \mathrm{U} / \mathrm{mL}$ de Taq ADN polimerasa (Promega, USA), $200 \mathrm{mM}$ de dNTP, $2 \mathrm{mM}$ de $\mathrm{MgCl}_{2}$ y $1 X$ de solución tampón.

El perfil térmico usado fue descrito previamente por Rubio et al. (6). Los productos de amplificación se analizaron por electroforesis en gel de agarosa al $2 \%$ teñido con bromuro de etidio. La realización de esta prueba desde la toma de muestra hasta su lectura se demora, en promedio, cuatro horas.

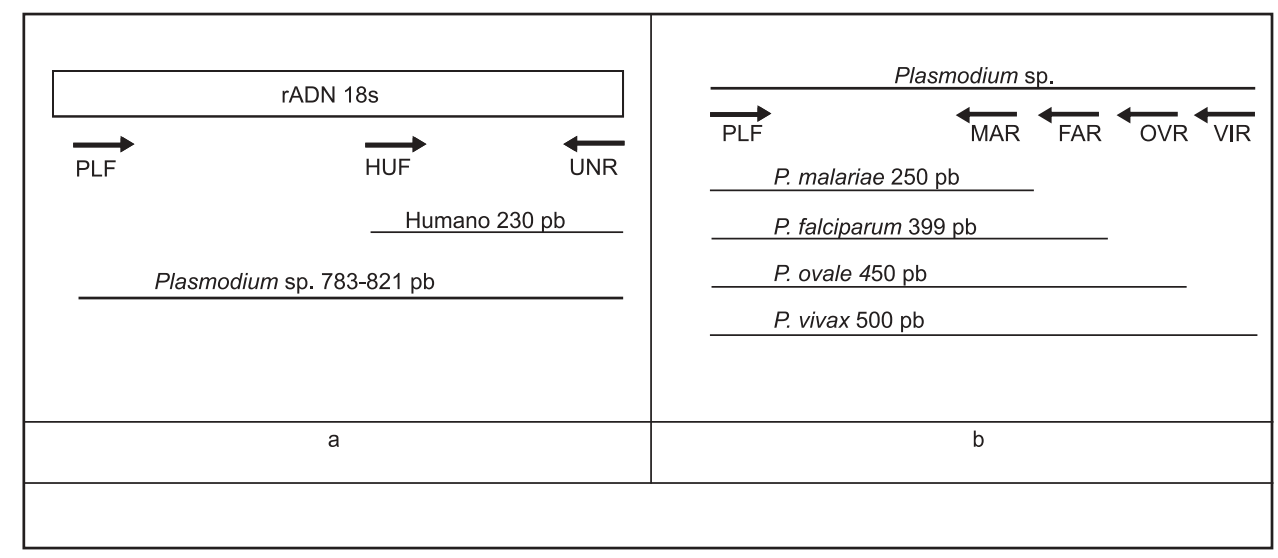

Figura 1. Esquema de las reacciones de amplificación por PCR para el diagnóstico de malaria. a. Primera reacción de amplificación. b. Segunda PCR múltiple. 
Cuadro 1. Características demográficas relacionadas con malaria de los pacientes del estudio de acuerdo con su clasificación de donantes "aceptados" o "rechazados".

\begin{tabular}{|c|c|c|}
\hline Característica & Aceptado $n=171(\%)$ & Rechazado $n=115(\%)$ \\
\hline \multicolumn{3}{|l|}{ Edad (años) } \\
\hline Rango & $18-60$ & $18-58$ \\
\hline Media & 32 & 31 \\
\hline \multicolumn{3}{|l|}{ Sexo } \\
\hline Masculino & $104(61)$ & $60(52)$ \\
\hline Femenino & $67(39)$ & $55(48)$ \\
\hline \multicolumn{3}{|l|}{$\begin{array}{l}\text { Area endémica de malaria visitada en los últimos } \\
12 \text { meses }\end{array}$} \\
\hline - Buenaventura, área urbana & $1(0,6)$ & $62(53,9)$ \\
\hline - Juanchaco-Ladrilleros (Buenaventura) & $3(1,8)$ & $29(25,2)$ \\
\hline - $\quad$ San Cipriano (Buenaventura) & $2(1,2)$ & $6(5,2)$ \\
\hline - $\quad$ Tumaco (Nariño) & & $4(3,5)$ \\
\hline - $\quad$ Sin dato & & $14(12)$ \\
\hline
\end{tabular}

Durante la validación de la prueba, previa a su aplicación en el estudio, se evaluó la sensibilidad del método en nuestras manos; para esto se realizó una curva de sensibilidad usando cultivos de $P$. falciparum de nuestro laboratorio (cepa de referencia MRA-285 P. falciparum).

\section{Análisis estadístico}

Se usó el programa SPSS 7.5 para Windows para el análisis estadístico. Se obtuvieron las frecuencias generales y se elaboraron tablas de contingencia. La prueba de ji al cuadrado se usó para determinar asociaciones entre donantes y edad, y donantes y sexo.

\section{Resultados}

Se incluyeron en el estudio 286 donantes en total, 171 en el grupo de "aceptados" y 115 en el grupo de "rechazados". En este banco de sangre, a diferencia de lo que sugiere el Ministerio de Protección Social, los donantes que han visitado una zona endémica son diferidos por seis meses y no por 12 meses como lo indica el Manual de normas técnicas y procedimientos para bancos de sangre. Por esta razón, seis donantes que habían visitado una zona endémica entre seis y doce meses previos, fueron aceptados. Las principales características de los sujetos de estudio se describen en el cuadro 1.

No se encontró asociación estadísticamente significativa entre los grupos de donantes con variables como la edad y el sexo $(p>0,05)$.

\section{Pruebas de laboratorio}

La gota gruesa, el ELISA-IgG, el ELISA HRPII y la PCR fueron negativos para los dos grupos de donantes, y para los controles negativos. Los resultados sólo fueron positivos para las muestras de los controles positivos. No fue posible evaluar la sensibilidad de las pruebas debido a la falta de resultados positivos entre los donantes de los dos grupos.

Con el protocolo de PCR usado con el cultivo de parásitos es posible detectar hasta $55 \mathrm{pg}$ del ADN del parásito (figura 2).

\section{Discusión}

En este estudio se compararon tres pruebas de laboratorio (gota gruesa, ELISA-IgG y ELISA HRPII) con la PCR para la tamización de malaria en donantes de un banco de sangre de Cali, Colombia. Todas las muestras evaluadas fueron negativas, lo cual sugiere que una prueba de laboratorio podría ser útil para evaluar objetivamente el riesgo de infección malárica entre los donantes potenciales en Cali y, posiblemente, en otras ciudades consideradas libres de transmisión de malaria en el país.

De acuerdo con las pruebas de laboratorio usadas en el estudio, ninguno de los donantes, tanto los "aceptados" como los que fueron "rechazados" por el riesgo de transmitir malaria, tenían la infección. La entrevista del banco de sangre es el método estándar actual para el proceso de tamización en 


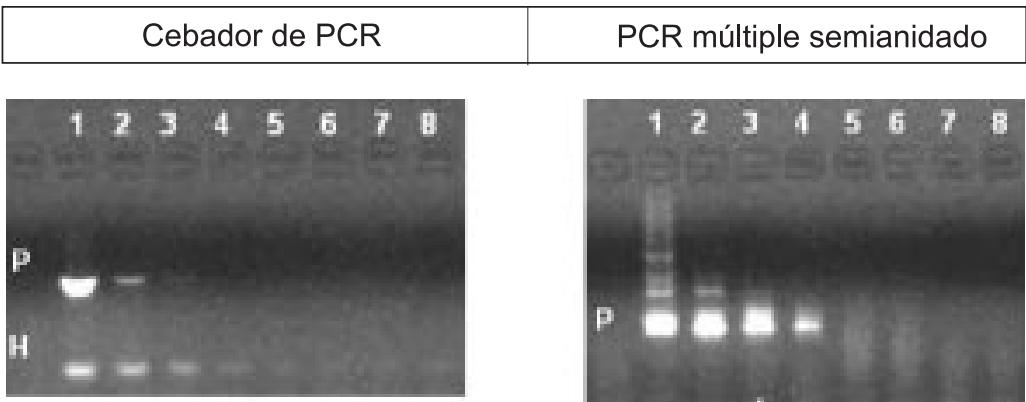

Figura 2. Curva de sensibilidad para la cepa de referencia MR4-285 con una parasitemia conocida de 2.000 parásitos $/ \mathrm{ml}$. 1: $55 \mathrm{ng}$ de ADN; 2: $5,5 \mathrm{ng} ; 3: 0,5 \mathrm{ng} ; 4: 55 \mathrm{pg} ; 5: 5,5 \mathrm{pg} ; 6: 55 \mathrm{fg} ; \mathbf{7}: 5,5 \mathrm{fg} ; \mathbf{8}: 0,5 \mathrm{fg}$.

$\mathrm{P}$ : banda de Plasmodium; H: banda humana

el caso de malaria y su objetivo es permitir detectar individuos con riesgo de portar la infección; sin embargo, a pesar de ser un buen instrumento para la tamización de malaria, su sensibilidad podría mejorar si se acompaña de una prueba de laboratorio que permita detectar los verdaderos positivos. Los donantes rechazados por el riesgo de transmitir malaria fueron negativos con las pruebas de laboratorio; por lo tanto, éstas fueron donaciones perdidas en ese momento.

Actualmente, la exclusión de un donante por riesgo de transmitir malaria se basa en la permanencia en una zona endémica; en este sentido, consideramos que aceptar donantes sólo sobre la base del tiempo de posible exposición a la infección puede no ser suficiente criterio para prevenir la malaria transmitida por transfusión. El estado de portador del parásito puede extenderse desde varios meses hasta años (12); una forma más segura de prevenir la malaria por transfusión sería adicionar una prueba de laboratorio para tamización de la infección.

En Colombia no se han publicado informes que permitan conocer la proporción de donantes que son rechazados por el riesgo de transmitir malaria, ni la incidencia de malaria por transfusión. En el Valle del Cauca se estimó que $23,6 \%$ de los donantes rechazados es debido a esta causa, la cual se considera la más importante (5). Sería interesante conocer estas cifras a nivel nacional para analizar la pertinencia de incluir una prueba para malaria en el proceso de selección de donantes o la implementación de estrategias que permitan una mejor selección de los donantes procedentes de zonas endémicas para malaria.
Con los resultados de este estudio no podemos sugerir cuál es el mejor método de tamización de malaria entre donantes de sangre. Sin embargo, por principio, en un banco de sangre, la sensibilidad de una prueba es el factor más importante a tener en cuenta para su selección.

En este sentido, la PCR ha mostrado ser una prueba altamente sensible y específica. Para este estudio se realizó una curva de sensibilidad de la prueba usando un cultivo con una parasitemia conocida de 2.000 parásitos/ $\mu \mathrm{l}$, y se detectó una parasitemia mínima de 0,2 parásitos/ $\mu$ l. Otros estudios usando esta técnica han detectado parasitemias entre 0,004 a 0,04 parásitos/ $\mu$ l de sangre (13-17). Teniendo en cuenta lo anterior, la PCR podría ser la prueba de elección. Sin embargo, aunque esta técnica puede ser la recomendada, la mayoría de nuestros bancos de sangre no poseen la capacidad técnica para realizarla y se hace necesario realizar estudios adicionales de costos para su aplicación.

ELISA es la técnica usada con más frecuencia en nuestros bancos de sangre (83\%) (18). Por esa razón, un ELISA para tamización de malaria podría ser más fácilmente implementada; además, resulta ser una prueba sencilla y poco costosa comparada con la PCR. El desarrollo de la prueba para malaria es similar a otros ELISA que se realizan de rutina en el laboratorio.

Los resultados de este estudio no permiten obtener conclusiones sobre la sensibilidad y la especificidad de este método para detectar casos de malaria; se hace necesario realizar ensayos con muestras positivas de donantes que permitan 
evaluar realmente la utilidad de la prueba para tamización. En la evaluación de esta prueba se debe tener en cuenta que algunos donantes pueden perderse debido a la posible persistencia prolongada de los anticuerpos, sobre todo en personas que son o han sido residentes de zonas endémicas $(19,20)$ y que, además, la prueba puede ser menos eficiente para detectar bajos niveles de anticuerpos, lo cual es común en la etapa inicial de la enfermedad, y puede resultar casos de falsos negativos $(20,21)$.

Si tenemos en cuenta que en Colombia las infecciones por $P$. vivax han sido reportadas hasta seis meses después de la exposición $(22,23)$, sugerimos que a los donantes potenciales que han estado en áreas endémicas para malaria en los seis meses previos o más, no se los rechace ni difiera, sino que se les practique una prueba para tamización de malaria en forma previa o posterior a la donación.

Una prueba de laboratorio con alta sensibilidad para la tamización de malaria también podría ser usada en los bancos de sangre ubicados en las áreas endémicas. De acuerdo con la guía del Ministerio de Protección Social, la gota gruesa es el método recomendado para usar en estos sitios, pero sus limitaciones en cuanto a su sensibilidad con parasitemias bajas es bien conocida $(24,25)$. Podría resultar más útil un método simple y objetivo, como la inmunodetección de anticuerpos u otras pruebas comerciales como el QBC® (Quantitative Buffy Coat, Becton Dickinson) que en algunos estudios ha mostrado tener una sensibilidad mayor que la gota gruesa $(16,26)$; sin embargo, en este caso se debe tener en cuenta la necesidad de un microscopio de fluorescencia para su lectura.

Sería valioso expandir la evaluación de tecnologías para detectar Plasmodium sp. en áreas endémicas para comparar la sensibilidad de los diferentes métodos y evaluar su utilidad en los bancos de sangre de lugares donde el riesgo de transmisión de malaria a través de las transfusiones es alto.

En Colombia, el déficit de unidades de sangre es realmente grave ( 1 unidad por 100 habitantes por año); por esta razón, el Ministerio de Protección Social necesita diseñar estrategias que permitan mejorar la disponibilidad de sangre pero sin incrementar el riesgo de infecciones en los receptores.

\section{Conflicto de interés}

Los autores declaran no tener conflicto de intereses en el manuscrito.

\section{Agradecimientos}

Al personal del Banco de Sangre donde se realizó el estudio, por su apoyo y colaboración, especialmente a su director. Al personal de CIDEIM que colaboró en la ejecución de la investigación, especialmente a Ana Marlén Obando, Carlos Rojas, Alejandra Cabrera y Mauricio Pérez. A Nancy Saravia y Lyda Osorio por la revisión y sugerencias al manuscrito.

\section{Financiación}

Este estudio se realizó con el apoyo financiero de la International Society for Infectious Disesases de Boston, EE.UU., el Banco de la República de Colombia (Proyecto 1.391) y los Laboratorios Cellabs de Australia.

\section{Referencias}

1. Beltrán DM, Ayala M, Ching R, Raad J. Política nacional en bancos de bangre en Colombia. Rev Mex Pat Clin 1998:45:163-75

2. Cortés A, Beltrán M, Olaya B, Hernández M. Riesgo de enfermedades infecciosas transmitidas por transfusión en el Valle del Cauca. Colombia Med 1999; 30:13-8.

3. Diario El País. Bancos de sangre con pocas consignaciones, Cali, 21 de septiembre de 2000; C5.

4. Beltrán M, Ayala M, Jara JH. La importancia de la encuesta de selección de donantes en el pretamizaje: experiencia de un banco de sangre de Bogotá, noviembre-diciembre de 1996. Biomédica 2000;20: 308-13.

5. Cortés A, Beltrán M, Olaya B, Hernández M. Epidemiología de la colección, proceso y uso de sangre y componentes sanguíneos en el Valle del Cauca, Colombia. Colombia Med 1999;30:5-12.

6. República de Colombia. Ministerio de Salud, Resolución 0901. Manual de Normas Técnicas, Administrativas y de Procedimientos de Bancos de Sangre (marzo de 1996).

7. Vergara J, Hurtado S, Alvarez V, Arévalo M, Herrera S. Caracterización de la transmisión de Plasmodium malarie en cuatro regiones colombianas endémicas de malaria. Biomédica 2001;21:53-61. 
8. Ortiz JM, Humanez JC, Pabón AL, Blair S. Prevalencia de anticuerpos antimaláricos en donantes del banco de sangre del Hospital Universitario San Vicente de Paúl de Medellín, Colombia. Biomédica 1999;19:303-10

9. Olaya P, Espinal CA. Detección de anticuerpos antiplasmodium por ELISA en donantes de sangre. Biomédica 1982;2:57-62.

10. Lemeshow $\mathbf{S}$, Taber $\mathbf{S}$. Lot quality assurance sampling: single and double sampling plans. World Health Stat $Q$ 1991;44:115-32.

11. Rubio JM, Benito A, Berzosa PJ, Roche J, Puente $S$, Subirats $M$ et al. Usefulness of seminested multiplex PCR in surveillance of imported malaria in Spain. J Clin Microbiol 1999;37:3260-4.

12. Bruce-Chwatt LJ. Transfusion malaria revisited. Trop Dis Bull 1982;79:827-40.

13. Humar A, Ohrt C, Harrington MA, Pilla D, Kain K. Parasight $F$ test compared with the polymerase chain reaction and microscopy for the diagnosis of Plasmodium falciparum malaria in travelers. Am J Trop Med Hyg 1997;56:44-8.

14. Rubio JM, Benito A, Roche J, Berzosa PJ, Garcia ML, Mico $\mathbf{M}$ et al. Semi-nested, multiplex polymerase chain reaction for detection of human malaria parasites and evidence of Plasmodium vivax infection in Equatorial Guinea. Am J Trop Med Hyg 1999;60:183-7.

15. Benito A, Rubio JM. Usefulness of seminested polymerase chain reaction for screening blood donors at risk for malaria in Spain. Emerg Infect Dis 2001;7: 1068.

16. Morassin B Fabre R, Berry A Magnaval JF. One year's experience with the polymerase chain reaction as a routine method for the diagnosis of imported malaria. Am J Trop Med Hyg 2002;66:503-8.
17. Snounou G, Viriyakosol $\mathbf{S}$, Zhu XP, Jarra $\mathbf{W}$, Pinheiro L, do Rosario $V$ et al. High sensitivity of detection of human malaria parasites by the use of nested polymerase chain reaction. Mol Biochem Parasitol 1993;61:315-20.

18. Durán MB, Guzmán MA. External evaluation of serology results in blood banks in Colombia. Rev Panam Salud Pública 2003;13:138-43.

19. Saeed AA, Mohsen A, Nasser IA, Onaizi MA, Kahtani SA, Dubois L. Malaria screening of blood donors in Saudi Arabia. Ann Saudi Med 2002;22:329-32.

20. Gilles HM, Warrell DA. Bruce-Chawatt's essential malariology. Third edition. London: Edward Arnold; 1993. p.92.

21. Voller A, Draper CC. Immunodiagnosis and seroepidemiology of malaria. Br Med Bull 1982;38:173-7.

22. Nicholls RS, Guerra MP. The changing behaviour of Plasmodium vivax in Colombia: relapses despite standard treatment with primaquine. Mem Inst Oswaldo Cruz 1994;89(Suppl.II):121.

23. Arias AE, Corredor A. Low response of Colombian strains of Plasmodium vivax to classical antimalarial therapy. Trop Med Parasit 1989;40:21-3.

24. Craig MH, Sharp BL. Comparative evaluation of four techniques for the diagnosis of Plasmodium falciparum infectious. Trans R Soc Trop Med Hyg 1997;91:279-82.

25. Bruce-Chwatt LJ. Transfusion malaria. Bull World Health Organ 1974;50:337-46.

26. Spielman A, Perrone JB, Teklehaimanot A, Balcha F, Wardlaw SC, Levine RA. Malaria diagnosis by direct observation of centrifuged samples of blood. Am J Trop Med Hyg 1988;39:337-42. 